\title{
Role of Glycine Receptors in Glycine-Induced LTD in Hippocampal CAI Pyramidal Neurons
}

\author{
Rong-Qing Chen 1,2,5, Shan-Hui Wang ${ }^{1,2,5}$, Wen Yao,, ${ }^{1, \text { Jing-Jing Wang }}{ }^{1,2}$, Fang Ji,2, Jing-Zhi Yan ${ }^{1,2}$, \\ Si-Qiang Ren ${ }^{1,2}$, Zheng Chen ${ }^{1,2}$, Su-Yi Liu' ${ }^{1,2}$ and Wei Lu*,1,2,3,4 \\ 'Department of Neurobiology, Nanjing Medical University, Nanjing, Jiangsu, People's Republic of China; ${ }^{2}$ Key Laboratory for Neurodegenerative \\ Disease of Jiangsu Province, Nanjing Medical University, Nanjing, Jiangsu, People's Republic of China; ${ }^{3}$ Laboratory of Reproductive Medicine, \\ Nanjing Medical University, Nanjing, Jiangsu, People's Republic of China; ${ }^{4}$ Key Laboratory for Human Functional Genomics of Jiangsu Province, \\ School of Basic Medical Sciences, Nanjing Medical University, Nanjing, Jiangsu, People's Republic of China
}

\begin{abstract}
Glycine in the hippocampus can exert its effect on both synaptic NMDA receptors (NMDARs) and extrasynaptic functional glycine receptors (GlyRs) via distinct binding sites. Previous studies have reported that glycine induces long-term potentiation (LTP) through the activation of synaptic NMDARs. However, little is known about the potential role of the activated GlyRs that are largely located in extrasynaptic regions. We report here that relatively high levels of glycine achieved either by exogenous glycine application or by the elevation of endogenous glycine accumulation with an antagonist of the glycine transporter induced long-term depression (LTD) of excitatory postsynaptic currents (EPSCs) in hippocampal CAI pyramidal neurons. The co-application of glycine with the selective GlyR antagonist strychnine changed glycine-induced LTD (Gly-LTD) to LTP. Blocking the postsynaptic GlyR-gated net chloride flux by manipulating intracellular chloride concentrations failed to elicit any changes in EPSCs. These results suggest that GlyRs are involved in Gly-LTD. Furthermore, this new form of chemical LTD was accompanied by the internalization of postsynaptic AMPA receptors and required the activation of NMDARs. Therefore, our present findings reveal an important function of GlyR activation and modulation in gating the direction of synaptic plasticity.

Neuropsychopharmacology (20II) 36, 1948-1958; doi:I0.1038/npp.201।.86; published online I8 May 20II
\end{abstract}

Keywords: glycine; glycine receptor; NMDA receptor; LTP; LTD; synaptic plasticity

\section{INTRODUCTION}

Glycine is a two-faceted bioactive molecule in the central nervous system (CNS) (Xu and Gong, 2010). On the one hand, glycine is a strychnine-insensitive co-agonist for NMDA receptors (NMDARs) that is essential for the activation of NMDARs (Johnson and Ascher, 1987; Kemp and Leeson, 1993; Danysz and Parsons, 1998). NMDAR has a critical role in neural development, learning and memory, sensory perception, and synaptic plasticity (ConstantinePaton and Cline, 1998; Zoghbi et al, 2000). Glycine can potentiate NMDAR-mediated currents through its highaffinity binding with NMDARs and produce or facilitate long-term potentiation (LTP) of the AMPA-subtype of glutamate receptor-mediated excitatory postsynaptic currents (EPSCs; Johnson and Ascher, 1987; Wilcox et al, 1996; Martina et al, 2004; Li et al, 2009; Lu et al, 2001; Zhang et al,

*Correspondence: Dr W Lu, Department of Neurobiology, Nanjing Medical University, Nanjing, Jiangsu 210029, People's Republic of China, Tel: +86 25 86862822, Fax: + 862586862822 ,

E-mail: lu@njmu.edu.cn

${ }^{5}$ These authors contributed equally to this work.

Received 18 October 2010; revised 30 March 2011; accepted 4 April 2011
2008). On the other hand, glycine is one of the main inhibitory neurotransmitters in the CNS (for reference, see Keck and White (2009)). Glycine receptors (GlyRs) have been studied in detail in the brain stem and spinal cord, where GlyRs are highly expressed. Additionally, accumulating evidence over the last decade has suggested that functional GlyRs are present throughout all regions in the hippocampus and have an important role in regulating excitability and plasticity. These strychnine-sensitive GlyRs, if located postsynaptically, are mostly found in extrasynaptic sites (Danglot et al, 2004). Because GlyRs present in hippocampal synapses are understood morphologically but not functionally (Keck and White, 2009), we sought to determine whether the activation of extrasynaptic GlyRs could contribute to the persistent plasticity of neurotransmission.

Because NMDARs have a substantially higher affinity for glycine than do GlyRs (Chattipakorn and McMahon, 2002; Vyklicky et al, 1990), endogenous glycine likely exerts its excitatory effect through NMDAR co-agonist binding. Under most physiological conditions, the glycine concentration in cerebrospinal fluid has been estimated to be in the low micromolar range (Westergren et al, 1994). However, under some pathophysiological conditions, such as brain 
ischemia and epilepsy, the concentration of glycine in the synaptic cleft can be quite elevated (Globus et al, 1991; Lasley, 1991). This raises the possibility that when excessive glycine is produced and accumulates in the synaptic cleft, it could spill over to extrasynaptic sites to activate functional GlyRs to exert an inhibitory effect. This hypothesis is supported by recent findings. Martina et al (2004) observed that a specific inhibitor of glycine transporter type 1 (GlyT1) causes a dose-dependent accumulation of glycine in the synaptic cleft. In contrast to the elevation of NMDAR currents and LTP induced by the application of low levels GlyT1 inhibitors, higher concentrations of GlyT1 inhibitors reduce NMDAR currents with no increase in LTP. These results suggest that the level of extracellular glycine could be an important factor for regulating the excitability of neurons. However, it is still unknown whether GlyRs have a role in this inhibitory effect. Another recent study further demonstrated that GlyR activation could mediate the acute inhibitory effects of glycine on excitatory postsynaptic potentials (EPSPs) (Song et al, 2006). It is of great importance to know whether and how GlyR activation by high levels of glycine accumulation, which opens GlyR-gated chloride channels, could induce persistent changes in EPSCs.

In the present study, we demonstrated that high levels of glycine induced chemical long-term depression (LTD) of EPSCs in CA1 pyramidal neurons. This effect was mainly attributable to modulatory effects of GlyRs. Our findings reveal an important function of GlyR activation and modulation in dictating the direction of synaptic plasticity.

\section{MATERIALS AND METHODS}

\section{Hippocampal Slice Preparation}

Male Sprague Dawley rats, 18-21 days old, were anesthetized with ethyl ether and decapitated. The entire brain was removed and coronal brain slices ( $350 \mu \mathrm{m}$ thickness) were cut using a vibrating blade microtome in ice-cold artificial cerebrospinal fluid (ACSF) containing (in $\mathrm{mM}$ ) $126 \mathrm{NaCl}$, $2.5 \mathrm{KCl}, 1 \mathrm{MgCl}_{2}, 1 \mathrm{CaCl}_{2}, 1.25 \mathrm{KH}_{2} \mathrm{PO}_{4}, 26 \mathrm{NaHCO}_{3}$, and 20 glucose. The $\mathrm{pH}$ was adjusted to 7.4. ACSF was bubbled continuously with carbogen $\left(95 \% \mathrm{O}_{2} / 5 \% \mathrm{CO}_{2}\right)$. Fresh slices were incubated in a chamber with carbogenated ACSF and recovered at $34{ }^{\circ} \mathrm{C}$ for at least $1.5 \mathrm{~h}$ before transfer to a recording chamber.

\section{Electrophysiological Studies}

Conventional whole-cell recordings were made with patch pipettes containing (in $\mathrm{mM}$ ) $132.5 \mathrm{Cs}$-gluconate, $17.5 \mathrm{CsCl}$, $2 \mathrm{MgCl}_{2}, 0.5$ EGTA, 10 HEPES, 4 ATP, and 5 QX-314 with the $\mathrm{pH}$ adjusted to 7.2 by $\mathrm{CsOH}$. The total intracellular $\mathrm{Cl}^{-}$ concentration is $21.5 \mathrm{mM}$. In the experiments performed with high chloride pipette solution, Cs-gluconate was not used in the pipette solution and the concentration of $\mathrm{CsCl}$ was changed to $132.5 \mathrm{mM}$. Under this condition, the total intracellular $\mathrm{Cl}^{-}$concentration is $136.5 \mathrm{mM}$. In experiments performed with low chloride pipette solution (Figure 4), the $\mathrm{Cl}^{-}$concentration in the pipette solution was lowered by changing the $\mathrm{CsCl}$ concentration from 17.5 to $6.5 \mathrm{mM}$ (total intracellular $\mathrm{Cl}^{-}$concentration was $10.5 \mathrm{mM}$ ). Hippocampal slices were perfused with ACSF at $34^{\circ} \mathrm{C}$, which was bubbled continuously with carbogen $\left(95 \% \mathrm{O}_{2} / 5 \% \mathrm{CO}_{2}\right)$. Stimulations were applied to Schaffer fibers through a constant current pulse delivered using a bipolar tungsten electrode. Evoked synaptic responses were evoked at $0.05 \mathrm{~Hz}$, except during the glycine application. In Supplementary Figure S1, evoked synaptic responses were also recorded during the glycine treatment. All recordings were performed at a $-65 \mathrm{mV}$ holding potential. The perfusion medium was switched to an $\mathrm{Mg}^{2+}$-free ACSF only when glycine was applied. EPSCs were recorded in ACSF perfusion media containing bicuculline methiodide (BMI, $10 \mu \mathrm{M})$ to block $\mathrm{GABA}_{\mathrm{A}}$ receptor-mediated inhibitory synaptic currents except for the experiment that $\mathrm{GABA}_{\mathrm{A}}$ function was kept intact (Figure 2a). CA1 pyramidal neurons were viewed under an upright microscope (ECLIPSE E600-FN, Normaski, Nikon Corporation, Tokyo, Japan) and recorded with an Axopatch-200B amplifier (Molecular Devices, Palo Alto, CA). Changes in EPSCs amplitude were examined during the last $5 \mathrm{~min}$ of recording. Data were low-pass filtered at $2 \mathrm{kHz}$ and acquired at $5-10 \mathrm{kHz}$. Recordings from each neuron lasted for at least $40-80 \mathrm{~min}$. The series resistance (Rs) in these recordings varied between 4 and $6 \mathrm{M} \Omega$. The Rs was always monitored during recordings for fear of re-sealing rupturing membrane, which will cause changes in both the kinetics and amplitude of the EPSCs. Cells in which the Rs or capacitance deviated by $>20 \%$ from initial values were excluded from the analysis. Additionally, cells with Rs $>20 \mathrm{M} \Omega$ at any time during the recording were excluded from the analysis. Data were collected with pClamp9.2 software and analyzed using Clampfit9.2 (Molecular Devices). For extracellular field potential recording, glass pipettes filled with $3 \mathrm{M} \mathrm{NaCl}$ (tip resistance of 2-5M $\mathrm{M}$ ) were positioned in the stratum radiatum of the CA1 region, and the field EPSPs (fEPSPs) were evoked with a bipolar tungsten electrode. The slope of fEPSP was calculated between 20 and $80 \%$ of the maximal amplitude and was used as an indicator of synaptic efficacy (Riekki et al, 2008).

\section{Pharmacology}

Channel blockers, including D,L-AP5, were purchased from Sigma-Aldrich. BMI was purchased from Tocris.

\section{Data Analysis}

All population data are expressed as the mean values \pm SEM. The raw data were normalized by averaged value of EPSCs during $10 \mathrm{~min}$ baseline recording. Within-group comparisons were performed using paired-sample $t$-tests, and differences between groups were compared using independent-sample $t$-test and ANOVA post hoc comparisons. An one-way ANOVA LSD test was used when equal variances were assumed. Differences were considered significant when $P<0.05$, and the significance for the homogeneity of variance test was set at 0.1 . Data are shown as the mean values \pm SEM. 


\section{RESULTS}

\section{Glycine Induced Chemical LTD in EPSCs}

We first performed whole-cell patch clamp recordings of evoked EPSCs in CA1 pyramidal neurons in hippocampal slices to examine whether the effects of glycine on EPSCs differed when applied at different concentrations. EPSCs were recorded at a $-65 \mathrm{mV}$ holding potential in an ACSF perfusion medium containing BMI $(10 \mu \mathrm{M})$ to block $\mathrm{GABA}_{\mathrm{A}}$ receptor-mediated inhibitory synaptic currents. The concentration of $\mathrm{Cl}^{-}$in the pipette solution was $21.5 \mathrm{mM}$. Following $10 \mathrm{~min}$ of stable baseline EPSCs recording, a range of concentrations of glycine $(0.05,0.2,0.6,1.0,1.2$, and $1.5 \mathrm{mM}$ ) was applied for $10 \mathrm{~min}$. The perfusates were switched to $\mathrm{Mg}^{2+}$-free ACSF only when glycine was applied to briefly activate NMDARs in CA1 pyramidal neurons. Changes in EPSCs amplitude were examined during the last $5 \mathrm{~min}$ of recording. Glycine at the 0.2 and $0.6 \mathrm{mM}$ concentrations significantly increased EPSCs and induced LTP of EPSCs (normalized amplitudes, $0.2 \mathrm{mM}, 1.59 \pm 0.17$, $n=6, P<0.01$ and $0.6 \mathrm{mM}, 2.07 \pm 0.27, n=6, P<0.01$, oneway ANOVA LSD test; Figure 1a and d). This result is consistent with previous studies in both slices and cultured cells (Bashir et al, 1990; Oliver et al, 1990; Lu et al, 2001). Surprisingly, when exogenous glycine reached $1.0 \mathrm{mM}$, no persistent change in EPSCs was observed ( $1.00 \pm 0.01, n=6$, $P=0.93$; Figure $1 \mathrm{~b}$ and $\mathrm{d})$. Further increasing the glycine concentration to $1.5 \mathrm{mM}$ produced LTD of EPSCs $(1.5 \mathrm{mM}$, $0.41 \pm 0.02, n=6, P<0.01$, one-way ANOVA $L S D$ test; Figure 1c and d and Supplementary Figure S1). This form of LTD remained when $\mathrm{GABA}_{\mathrm{A}}$ receptors were intact
(Figure 2a) and was not associated with substantial alterations in input resistance or holding current (Supplementary Figure S2). Gly-LTD was not due to the rundown of EPSCs caused by the deterioration of the recorded cells or to an adverse effect on the recording of the cells during glycine treatment because glycine, at this concentration, does not display toxic effects on nerve cells (Barth et al, 2005; Wallis et al, 1995; Newell et al, 1997).

Because GlyR activation may only induce LTD when the intracellular contents of the neuron are dialyzed, we also examined whether this LTD occurred using extracellular field potential recordings. These results display similar observations and confirm that the activation of GlyRs can induce LTD of fEPSPs $(0.49 \pm 0.06, n=5$; Figure $2 \mathrm{~b})$. Our present results suggest that increasing the level of exogenously applied glycine shifted the excitation-inhibition balance toward inhibition and induced persistent depression in EPSCs. We also performed these experiments with a high $\mathrm{Cl}^{-}$concentration pipette solution $\mathrm{CCl}^{-}$ $132.5 \mathrm{mM}$ ) and found that the above observation was still detected but that the concentrations of glycine necessary to produce the effects of interest tended to be lower (Supplementary Figure S3).

\section{Gly-LTD Required the Activation of GlyRs}

We further investigated the mechanisms by which glycineinduced LTD at high concentrations. Glycine mainly exerts its action at two sites: the NMDAR co-agonist binding site (site B) and the GlyR site (site A), which mediate excitatory and inhibitory actions, respectively. We hypothesized that
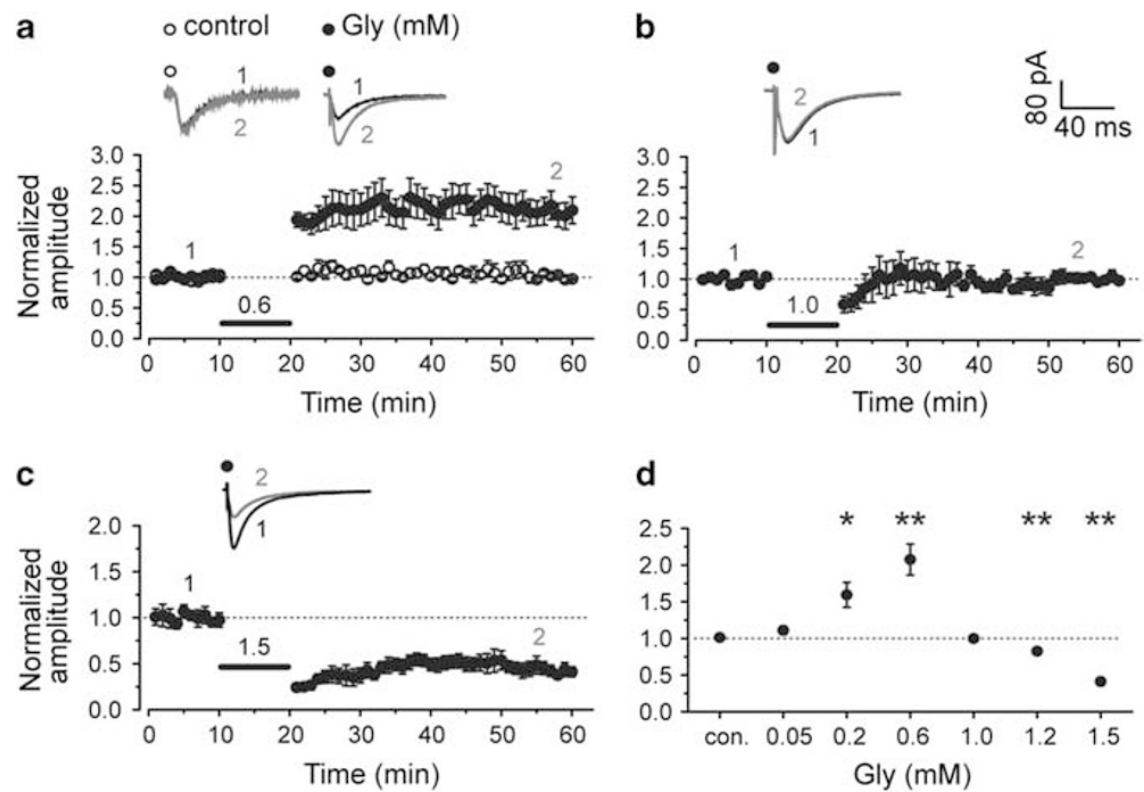

Figure I Glycine induced bidirectional persistent changes in EPSCs in a dose-dependent manner. (a) Application of $0.6 \mathrm{mM} \mathrm{glycine} \mathrm{for} 10 \mathrm{~min}$ in $\mathrm{Mg}^{2+}$ free ACSF caused significant potentiation of evoked AMPAR-mediated EPSCs when cells were held at $-65 \mathrm{mV}$ in a conventional whole-cell patch configuration $(n=6)$. EPSCs were recorded in an ACSF perfusion medium containing bicuculline methiodide $(B M I, 10 \mu M)$ to block $\mathrm{GABA}_{\mathrm{A}}$ receptormediated inhibitory synaptic currents. However, I0-min treatment of $\mathrm{Mg}^{2+}$-free ACSF alone failed to produce any persistent change in EPSCs (control). In this and all of the following figures, unless stated, ACSF was always kept in $1.0 \mathrm{mM} \mathrm{Mg}{ }^{2+}$ before and after glycine treatment, and traces above the graph show averaged AMPAR-mediated EPSCs chosen at the times indicated on the graph. (b) When the concentration of glycine increased to $1.0 \mathrm{mM}$, no persistent change in EPSCs was observed $(n=6)$. (c) In all, $1.5 \mathrm{mM}$ glycine treatment in $\mathrm{Mg}^{2+}$-free ACSF induced LTD of AMPAR-mediated EPSCs $(n=6)$. (d) Summary of data comparing persistent changes in EPSCs induced by glycine across a range of concentrations $(0.05,0.2,0.6,1.0,1.2$, and I.5 mM). $* P<0.05$; ** $P<0.01$, compared with control, ANOVA LSD test. 

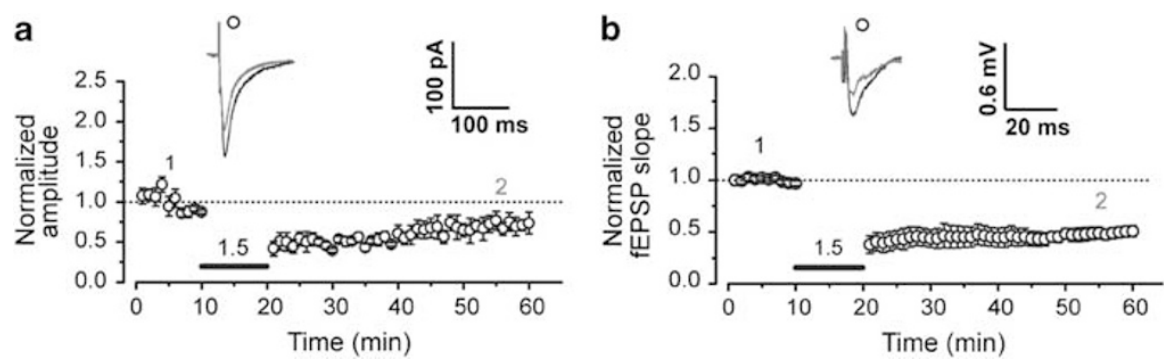

Figure 2 Gly-LTD was observed when function of $\mathrm{GABA}_{A}$ receptors was intact or when recording excitatory field potential. (a) Glycine (I.5 mM) induced LTD when GABA $A$ receptors are functional $(n=4)$. The bicuculline was omitted in this experiment. (b) GlyRs induced LTD of fEPSPs. Field potential recording reveals persistent depression after brief glycine $(1.5 \mathrm{mM})$ treatment $(n=5)$. The sample traces above the graph show averaged currents chosen at the times indicated on the graphs.
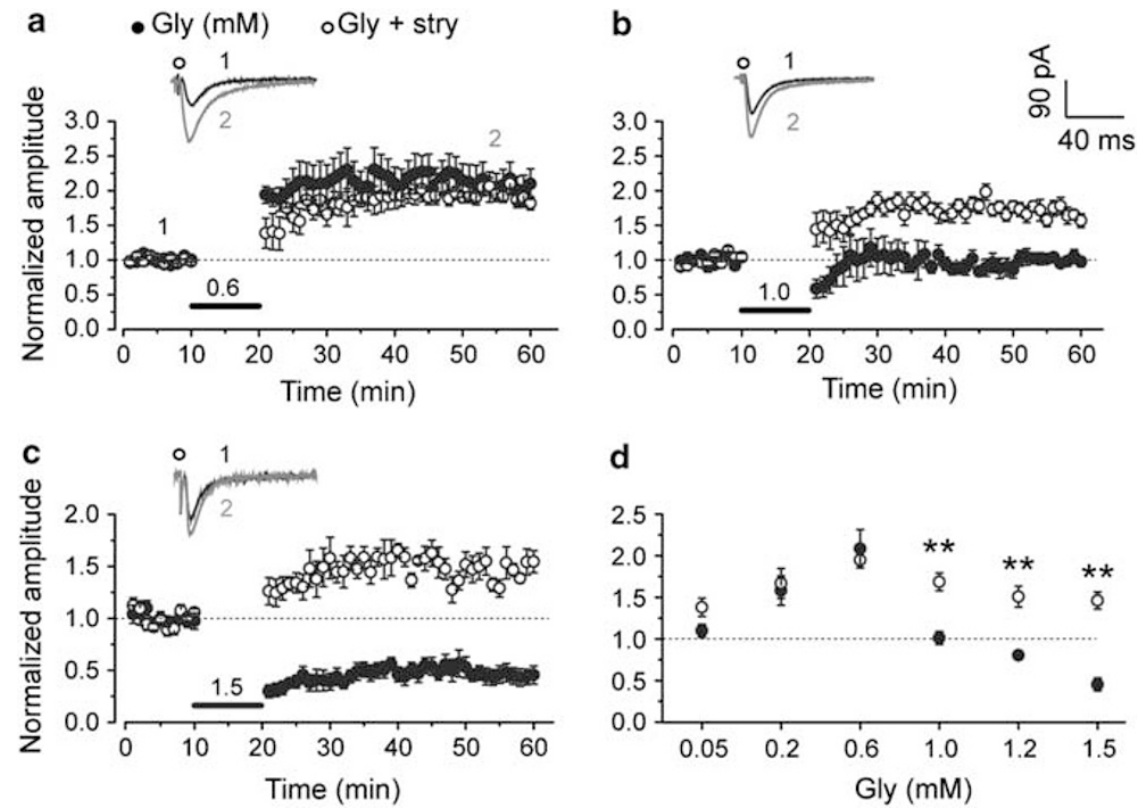

Figure 3 The Gly-LTD was mainly attributable to the activation of GlyRs by glycine. (a) The chemical LTP induced by $0.6 \mathrm{mM}$ glycine was unaffected by the specific GlyR antagonist, strychnine $(5 \mu \mathrm{M} ; n=6)$. (b) When the concentration of glycine was increased to $1.0 \mathrm{mM}$, the co-application of I.0 mM glycine with the GlyR antagonist, strychnine $(5 \mu M)$, induced LTP $(n=6)$. (c) The chemical LTD induced by 1.5 mM exogenous glycine was switched to LTP following GlyR blockade by the specific GlyR antagonist, strychnine $(5 \mu \mathrm{M} ; n=6)$. This reversal in polarity was incomplete because the potentiation magnitude after reversal was lower than after $0.6 \mathrm{mM}$ treatment $(P=0.02$, independent-samples $t$-test). The persistent changes induced by 0.6 and $1.0 \mathrm{mM}$ glycine (control in $a$ and $b$ respectively) were borrowed from the data in Figure l. (d) Summary of data displaying the effect of strychnine on persistent changes in EPSCs induced by glycine across a range of concentrations $(0.05,0.2,0.6,1.0,1.2$, and $1.5 \mathrm{mM})$. $* * * P<0.01$, compared with glycine alone.

the suppressive effect produced by high concentrations of glycine was mediated by the activation of GlyRs ( site A) in contrast to Gly-LTP which was mediated by the activation of synaptic NMDARs (site B). To examine this hypothesis, we first detect whether direct treatment of glycine at a dosage inducing LTD could elicit glycine currents. As expected, glycine-generated currents with either normal $(21.5 \mathrm{mM})$ or high intracellular $\mathrm{Cl}^{-}$concentration (136.5 mM; Supplementary Figure S3). We further used a specific antagonist of GlyRs to determine whether the glycine-induced depression in EPSCs was affected by the blocker. Glycine-induced LTD (Gly-LTD) was totally abolished and switched to LTP with the continuous perfusion of the slices with the specific GlyR antagonist, strychnine $(5 \mu \mathrm{M}$; LTP, $1.46 \pm 0.10, n=6$, compared with LTD $0.45 \pm 0.07, n=6, P<0.01$, ANOVA $L S D$ test; Figure $3 \mathrm{c}$ and d). Strychnine treatment after glycine application failed to exert any obvious effect during the expression phase of Gly-LTD, which suggested that this polarity reversal effect by strychnine only occurred during the induction phase (Supplementary Figure S4). Gly-LTP was not affected by strychnine treatment $(n=6$; Figure 3a and d). Although no obvious change in EPSCs was observed after brief treatment of $1.0 \mathrm{mM}$ glycine, LTP was detected when strychnine $(5 \mu \mathrm{M})$ was co-applied with glycine $(n=6$; Figure $3 \mathrm{~b}$ ). It is noteworthy that the reversal of the plasticity polarity was incomplete because the potentiation magnitude of LTP following reversal was lower than LTP induced by $0.6 \mathrm{mM}$ glycine $(P<0.01$, ANOVA $L S D$ test, Figure $3 \mathrm{a}$ and d). Moreover, we also observed that glycine, at relative high levels, generated currents in a dose-dependent manner in the presence of a high intracellular $\mathrm{Cl}^{-}$concentration (Supplementary Figure S3). These results provide solid 
support to our hypothesis that Gly-LTD requires the activation of GlyRs.

\section{Absence of Changes in EPSCs Following Blockade of GlyR-Gated Chloride Currents}

The activation of GlyRs by glycine allows GlyR-gated $\mathrm{Cl}^{-}$ channel-mediated currents and $\mathrm{Cl}^{-}$flux. By manipulating the $\mathrm{Cl}^{-}$concentration in the recording pipette to block net chloride flux upon GlyR activation, we examined whether Gly-LTD was mediated by postsynaptic GlyR-gated chloride currents. We decreased the $\mathrm{Cl}^{-}$concentration in the pipette solution by lowering the $\mathrm{CsCl}$ concentration from 17.5 to $6.5 \mathrm{mM}$ (total intracellular $\mathrm{Cl}^{-}$concentration was $10.5 \mathrm{mM}$ ). As a result, the reversal potential for the $\mathrm{Cl}^{-}$current was adjusted to be approximately the resting potential of $-65 \mathrm{mV}$. When holding the recorded neurons at resting potential, there was no obvious driving force for $\mathrm{Cl}^{-}$flux upon GlyR activation. After this manipulation, high concentrations of glycine failed to induce any changes in EPSCs (1.08 $\pm 0.12, n=6$, compared with baseline, $n=6$, $P>0.05$, paired-samples $t$-test; Figure $4 \mathrm{~b}$ and c). By contrast, the Gly-LTP was not affected by this manipulation $(n=6$; Figure 4a). Increasing the level of glycine to $2.0 \mathrm{mM}$ still did not produce LTD (Figure 4d). A reversal of the plasticity polarity was not detected. Because the normalized ratio of EPSCs actually represents the sum of Gly-LTP and Gly-LTD and a normalized ratio of 1 could represent an equal magnitude of Gly-LTP and Gly-LTD, the absence of changes in EPSCs here might indicate the decrease of glycine-induced depression caused by postsynaptic $\mathrm{Cl}^{-}$ manipulation, restoring the balance of Gly-LTP and GlyLTD, or indicate the increase of Gly-LTP without any change in Gly-LTD. Further strychnine $(5 \mu \mathrm{M})$ treatment in combination with this intracellular $\mathrm{Cl}^{-}$manipulation completely reversed the polarity of plasticity from LTD to LTP with a potentiation magnitude comparable to the LTP produced by low concentrations of glycine (low $\mathrm{Cl}^{-}+$ strychnine, $1.59 \pm 0.16, n=6$, compared with Gly-LTD, $n=6, P<0.01$, one-way ANOVA $S-N-K$ test; compared with Gly-LTP, $n=6, P=0.08$, independent-samples $t$-test; Figure $4 \mathrm{~b}$ and $\mathrm{c})$. These data suggest that glycine-induced depression was largely attenuated when the holding potential is set at the $\mathrm{Cl}^{-}$equilibrium potential. Furthermore, when neurons were held at a holding potential $(-30 \mathrm{mV})$ more positive than the $\mathrm{Cl}^{-}$equilibrium potential during glycine application, Gly-LTD was still observed (Supplementary Figure S5). These data confirm the contribution of postsynaptic GlyRs to the induction of Gly-LTD.

\section{Endogenous Glycine Induced Gly-LTD}

All of the above observations were produced by exogenous glycine. We sought to determine whether endogenously released glycine could also produce chemical LTD in EPSCs a

- control (Gly, mM) $\bullet+$ low $\mathrm{Cl}^{-}$

$\Delta+$ low $\mathrm{Cl}^{-}$\& stry

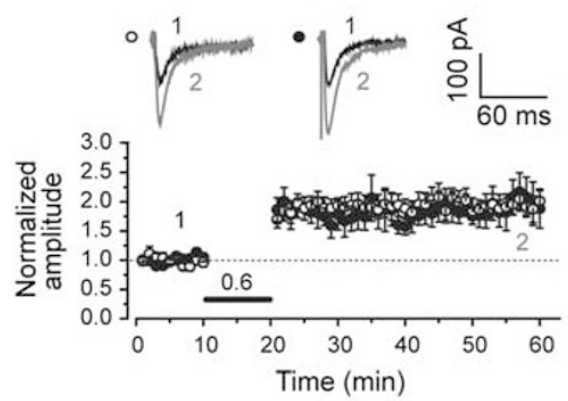

C
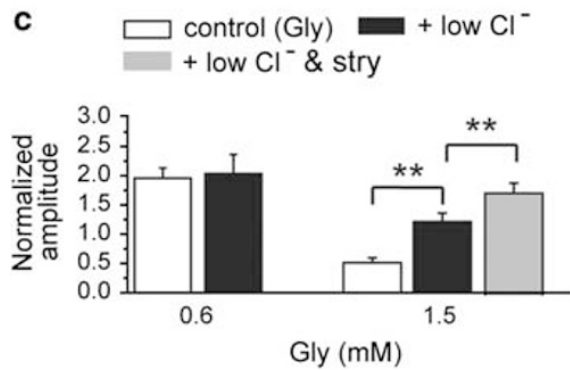

b

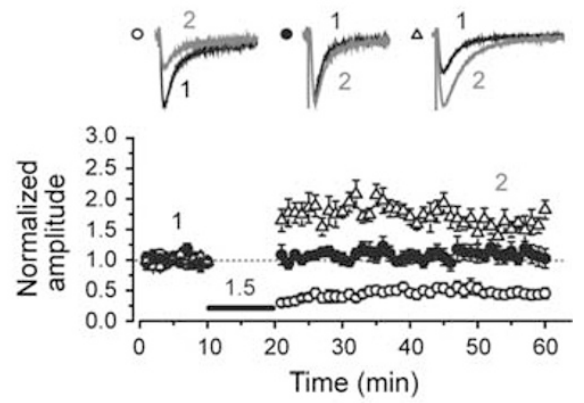

d

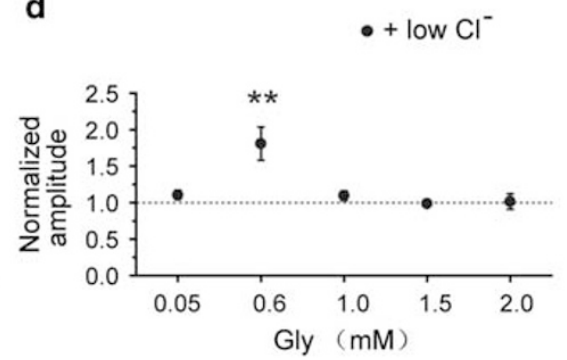

Figure 4 Suppression of EPSCs was abolished by decreasing the postsynaptic chloride driving force. (a) A decrease in the postsynaptic chloride driving force obtained by reducing the intracellular $\mathrm{Cl}^{-}$concentration from 21.5 to $10.5 \mathrm{mM}$, which adjusted the $\mathrm{Cl}^{-}$reversal potential to close to the resting potential $(-65 \mathrm{mV})$, failed to exert any effect on the LTP induced by $0.6 \mathrm{mM}$ glycine $(n=6)$. (b) In contrast, the same manipulation completely abolished the suppression of EPSCs induced by $1.5 \mathrm{mM}$ glycine $(n=6)$. Further GlyR antagonist strychnine $(5 \mu \mathrm{M})$ treatment along with a reduced intracellular $\mathrm{Cl}^{-}$ concentration, completely switched LTD to LTP with a comparable potentiation magnitude to the potentiation induced by $0.6 \mathrm{mM}$ glycine ( $n=6$ ). (c) Statistical plotting of data showing differential effects of the manipulation of intracellular $\mathrm{Cl}^{-}$concentrations on persistent changes in EPSCs induced by glycine. $* * P<0.01$, compared between indicated groups. (d) Summary of data displaying effect of $\mathrm{Cl}^{-}$on persistent changes in EPSCs induced by glycine across a range of concentrations $(0.05,0.6,1.0,1.5$, and $2.0 \mathrm{mM})$. ${ }^{*} P<0.01$, compared with all the other groups. 
similar to exogenous glycine. To test this possibility, we inhibited type 1 and type 2 glycine transporters to observe how the accumulation of extracellular glycine could affect EPSCs. A high-affinity glycine transporter type 1 (GlyT1) has been described in glial cells and glutamatergic neurons (Cubelos et al, 2005), but glycine transporter type 2 (GlyT2) is expressed by calbindin-positive GABAergic interneurons in the CA1 (Danglot et al, 2004). Blockade of the glycine transporter potentiates NMDAR currents, which suggests that the suppression of the uptake of glycine causes the accumulation of endogenous glycine in the synaptic cleft (Martina et al, 2004). Sarcosine is a potent GlyT1 blocker and displays dose-dependent GlyT1 inhibition (Tsen et al, 2000). A 10-min application of a sub-saturating concentration of sarcosine $(2.0 \mathrm{mM})$ in $\mathrm{Mg}^{2+}$-free perfusion medium induced LTP of EPSCs $(1.86 \pm 0.23, n=6, P<0.01$, pairedsamples $t$-test; intracellular $\mathrm{Cl}^{-}$concentration is $21.5 \mathrm{mM}$; Figure $5 \mathrm{a}$ ). In contrast, perfusing slices with a saturating concentration of sarcosine $(5.0 \mathrm{mM})$ produced LTD $(0.62 \pm 0.06, n=6, P<0.01$; Figure $5 \mathrm{~b})$. The currents induced by treatment of GlyT1 blocker sarcosine were observed (Supplementary Figure S6). Moreover, the GlyR antagonist, strychnine $(5 \mu \mathrm{M})$, switched LTD to LTP $(1.37 \pm 0.07, n=6, P<0.01$; Figure $5 \mathrm{~b}$ and $\mathrm{g})$. This reversal of the plasticity polarity was incomplete because the potentiation magnitude of LTP following reversal was lower than LTP induced by a $2.0 \mathrm{mM}$ concentration of the GlyT1 blocker, sarcosine, alone $(P<0.05$, ANOVA LSD test; Figure $5 \mathrm{~b}$ ). The differences in plasticity induced by the GlyT1 blocker at different concentrations and the switch in plasticity polarity induced by the GlyR antagonist were similar to the effects caused by exogenous glycine at different levels. These results demonstrated that endogenous glycine at relatively high levels also induced persistent depression in EPSCs. In contrast, the GlyT2-specific blocker, ALX1393 $(1 \mu \mathrm{M})$, failed to display any significant influence on EPSCs, which suggested that GlyT2-mediated glycine uptake was not a major factor in the buffering of extracellular glycine in this case (Supplementary Figure S7).

In addition to the level of GlyT1 blocker, the time course of action of this GlyT1 blocker could also be an important factor that affected the accumulation of glycine in the synaptic cleft. A longer time course of action will cause more glycine accumulation. To test this assumption, we treated the slices with the GlyT1 blocker, sarcosine, for different lengths of time. Extending the application time for $2.0 \mathrm{mM}$ sarcosine from 10 to $30 \mathrm{~min}$ caused LTD rather than LTP $(0.55 \pm 0.08, \quad n=5, \quad P<0.01$, paired-samples $t$-test; Figure $5 c$ and $h$ ). In contrast, shortening the application time for $5.0 \mathrm{mM}$ sarcosine from 10 to $4 \mathrm{~min}$ caused LTP rather than LTD of EPSCs $(1.53 \pm 0.09, n=5, P<0.01$; Figure $5 \mathrm{~d}$ and $\mathrm{h}$ ). These results strongly suggested that the accumulation of glycine following GlyT1 blockade was a progressive process, and the level of extracellular glycine can be a critical factor in the regulation of EPSCs.

Recent studies have uncovered more functions of sarcosine beyond its antagonizing effect on GlyT1 (Zhang et al, 2009a, b). Therefore, it is possible that our results with sarcosine were caused by these non-specific effects. To check this possibility, we used another more specific GlyT1 blocker, N-[3-([1,1-Biphenyl]-4-yloxy)-3-(4-fluorophenyl)propyl]-N-methylglycine (NFPS), to examine whether the endogenous accumulation of glycine due to GlyT1 blockade could induce Gly-LTD. Saturating concentration of NFPS $(2.0 \mu \mathrm{M})$ in $\mathrm{Mg}^{2+}$-free perfusion medium indeed elicited a persistent depression of EPSCs $(0.76 \pm 0.06, n=7, P<0.01$, paired-samples $t$-test; Figure $5 \mathrm{f}$ and $\mathrm{i}$ ), which was reversed by the GlyR blocker, strychnine $(n=6, P<0.01)$. In contrast, a sub-saturating concentration of NFPS $(0.2 \mu \mathrm{M})$ induced LTP of EPSCs $(1.26 \pm 0.07, n=6, P<0.01$, Figure $5 \mathrm{e}$ and i). These results are consistent with the above data with sarcosine and further confirm that endogenous glycine can induce LTD of EPSCs in CA1 pyramidal neurons.

\section{AMPAR Internalization Is Involved in Gly-LTD}

Rapid SNARE-dependent AMPAR insertion into the postsynaptic surface is responsible for increased AMPAR surface expression and enhanced synaptic transmission in LTP of AMPAR EPSCs (Luscher et al, 1999; Lu et al, 2001; Lee et al, 2004; Boehm et al, 2006; Jaskolski et al, 2007), whereas dynamin-dependent AMPAR internalization is responsible for reduced AMPAR surface expression (Carroll et al, 2001; Malenka and Bear, 2004). To investigate whether the Gly-LTD in AMPAR-mediated EPSCs was due to postsynaptic AMPAR internalization, we loaded cells with a specific dynamin-dependent endocytosis inhibitor, D15 $(2 \mathrm{mM})$, which specifically interferes with the binding of dynamin to amphiphysin (Luscher et al, 1999; Morishita et al, 2005). We were then able to examine whether Gly-LTD could be induced under these conditions (Kang et al, 2005; Tojima et al, 2007). We found that there were no obvious changes in EPSCs following D15 treatment $(0.99 \pm 0.04$, $n=7$, compared with baseline, paired-samples $t$-test, $P>0.05$; Figure $6 \mathrm{~b}$ and $\mathrm{d}$ ). The absence of changes in EPSCs here might indicate the decrease of glycine-induced depression caused by blockade of endocytosis, making GlyLTP and Gly-LTD restore balance. In contrast, D15 in the pipette solution did not alter Gly-LTP $(1.86 \pm 0.21, n=5$, $P>0.05$; Supplementary Figure S8), whereas the specific SNARE-dependent exocytosis inhibitor, tetanus toxin (TeTx, $0.1 \mu \mathrm{M})$, completely blocked Gly-LTP induction $(1.05 \pm 0.03, n=6$, compared with baseline, $P>0.05$, paired-samples $t$-test; Figure 6a and c) but failed to affect Gly-LTD (Supplementary Figure S9). These data suggested that AMPAR internalization was involved in Gly-LTD of EPSCs in CA1 pyramidal neurons.

\section{Both Gly-LTP and Gly-LTD Depend on NMDAR Activation}

To examine whether Gly-LTP and Gly-LTD depend on NMDAR activation, we co-applied a competitive NMDAR antagonist (AP5, $100 \mu \mathrm{M})$ with glycine. We detected no obvious changes in EPSCs following this treatment $(0.6 \mathrm{mM}$ Gly + AP5 $1.0 \pm 0.04, n=6$, compared with baseline, $P=0.9$, paired-samples $t$-test; $1.0 \mathrm{mM}$ Gly + AP5, $1.0 \pm 0.03, n=6$, compared with baseline, $P=0.6$, paired-samples $t$-test; Figure $7 \mathrm{a}-\mathrm{c})$. Moreover, we conducted the above studies in $1.0 \mathrm{mM} \mathrm{Mg}^{2+}$ perfusion solution when glycine was applied. Because of the $\mathrm{Mg}^{2+}$ block of NMDARs, this treatment could obstruct the selective activation of synaptic NMDAR. As a result, no LTP or LTD was detected $(0.6 \mathrm{mM}$ 

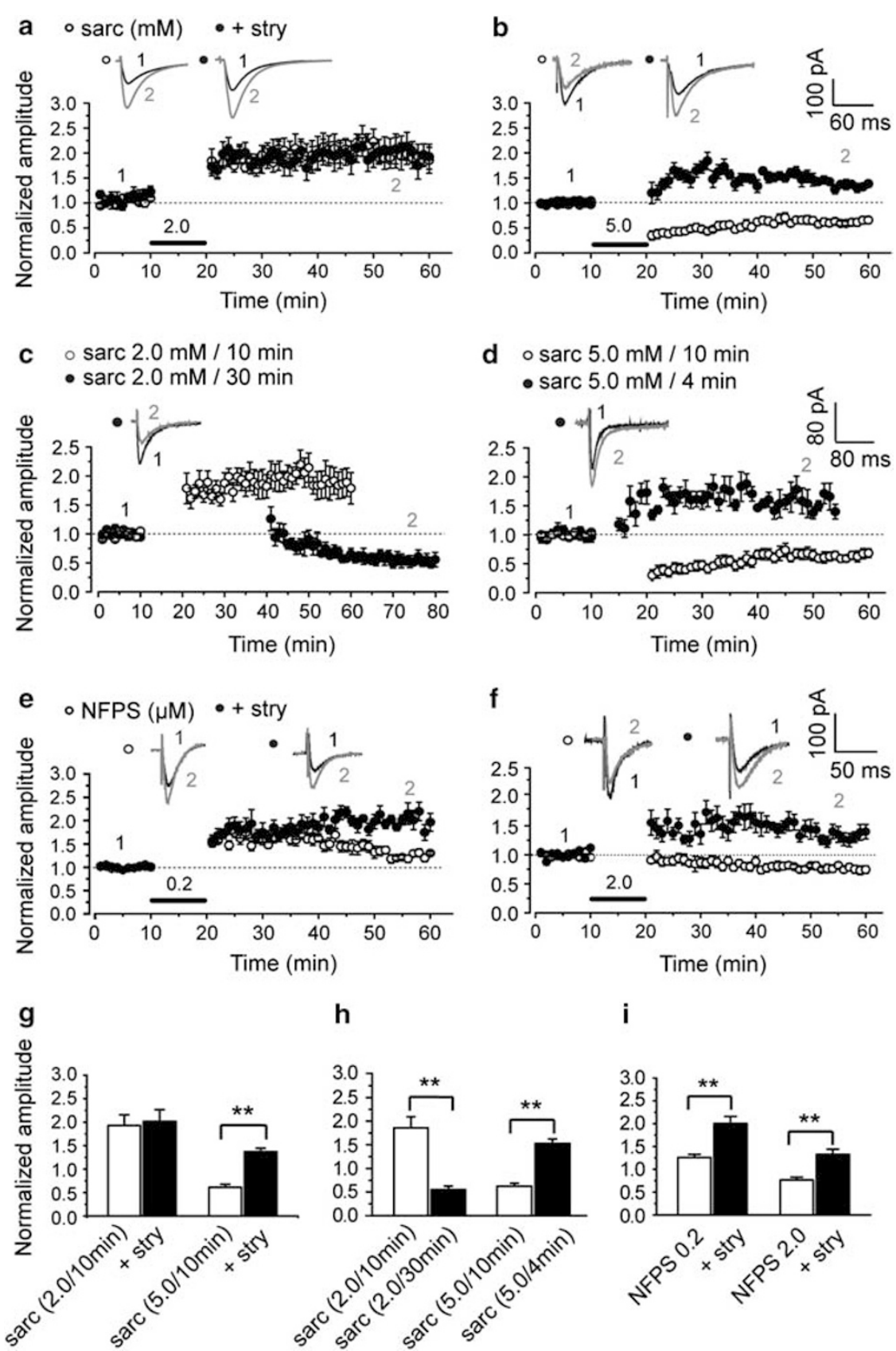

$\mathrm{h}$

i

Figure 5 Elevating endogenous glycine concentration by GlyTI blockade induced persistent changes in EPSCs. (a) Blocking GlyTI with a sub-saturating concentration of the specific GlyTI antagonist, sarcosine $(2.0 \mathrm{mM})$, in $\mathrm{Mg}^{2+}$-free ACSF for $10 \mathrm{~min}$, which increased endogenous glycine levels in the synaptic cleft, induced LTP of EPSCs $(n=6)$. This LTP was not affected by simultaneous strychnine $(5 \mu M)$ treatment $(n=6)$. (b) In contrast, blocking GlyTI with a saturating concentration of sarcosine $(5.0 \mathrm{mM})$ instead produced LTD, which could be partially reversed by strychnine $(5 \mu \mathrm{M})$ treatment $(n=6)$. This reversal of the plasticity polarity was incomplete because the potentiation magnitude of LTP following reversal was lower than LTP induced by a $2.0 \mathrm{mM}$ concentration of the GlyTI blocker, sarcosine, alone $(P=0.004$, independent-samples $t$-test). (c) Extending the application time of a sub-saturating concentration of sarcosine $(2.0 \mathrm{mM})$ from 10 to $30 \mathrm{~min}$ led to more endogenous glycine accumulation in the synaptic cleft, which induced LTD of EPSCs $(n=5)$. (d) Shortening the application time of a saturating concentration of sarcosine $(5.0 \mathrm{mM})$ from 10 to 4 min led to reduced endogenous glycine accumulation in the synaptic cleft and induced LTP of EPSCs $(n=5)$. (e) Blocking GlyTI with a sub-saturating concentration of a more specific GlyTI antagonist. NFPS $(0.2 \mu \mathrm{M})$ induced LTP of EPSCs $(n=6)$. (f) Blocking GlyTI with a saturating concentration of NFPS $(2.0 \mu M, n=7)$ instead produced LTD that was reversed by strychnine $(5 \mu \mathrm{M})$ treatment $(n=6)$. (g) Statistical plotting of data displaying the effect of GlyR blockade on persistent changes in EPSCs induced by sub-saturating or saturating concentrations of the GlyTI antagonist, sarcosine. (h) Summary of data displaying the effect of different acting times of sub-saturating or saturating concentrations of sarcosine on persistent changes in EPSCs. (i) Summary of data showing the effect of GlyR blockade on persistent changes in EPSCs induced by sub-saturating or saturating concentrations of the GlyTI antagonist, NFPS. ** $P<0.0$ I, compared between the indicated groups.

Gly, $1.1 \pm 0.07, n=6$, compared with baseline, $P=0.3$, paired-samples $t$-test; $1.5 \mathrm{mM}$ Gly, $1.0 \pm 0.04, n=6$, compared with baseline, $P=0.2$, paired-samples $t$-test; Figure
$7 a-c)$. These data strongly suggest that both LTP and LTD induced by glycine at different concentrations depend on NMDAR activation. 
a $\circ 0.6 \mathrm{mM}$ Gly $\bullet 0.6 \mathrm{mM}$ Gly + TeTx

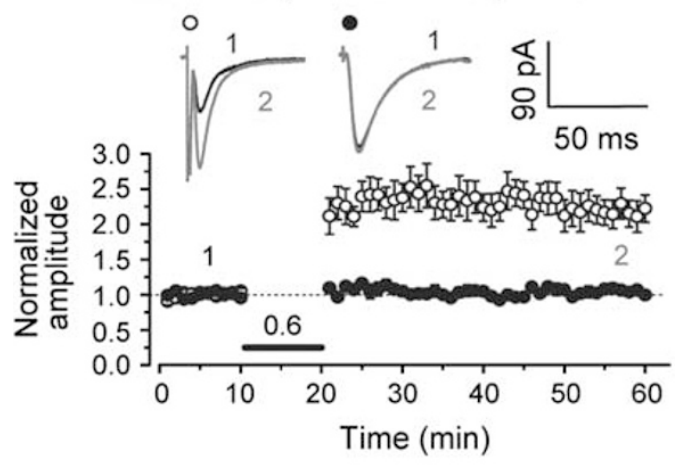

b $\quad$ o $1.5 \mathrm{mM}$ Gly $\bullet 1.5 \mathrm{mM}$ Gly + D15
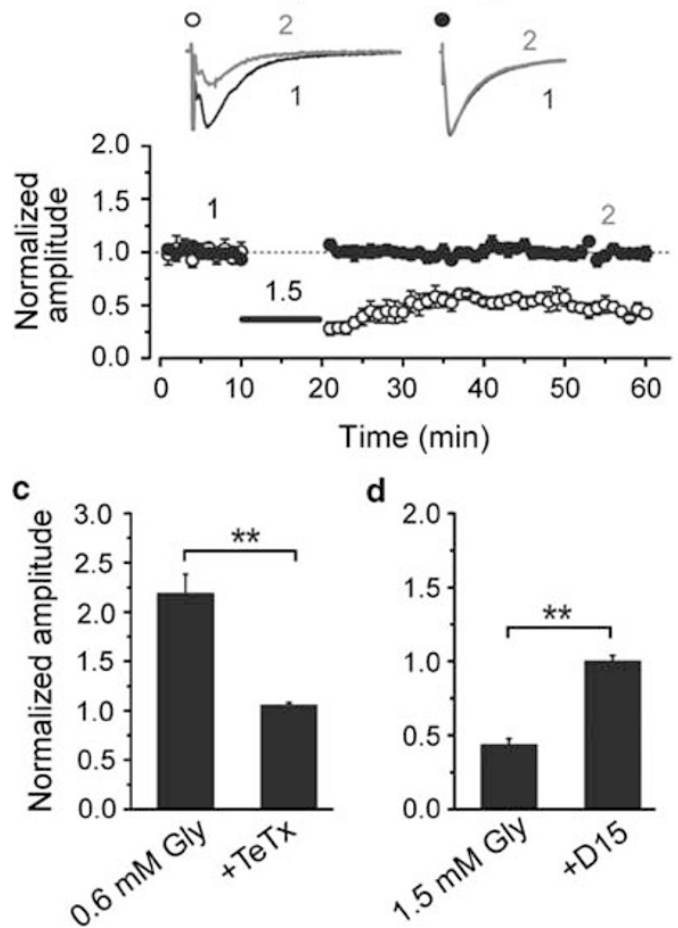

Figure 6 Gly-LTD was accompanied by rapid internalization of AMPA receptors in CAI pyramidal neurons. (a) Glycine-induced LTP disappeared when loading recorded cells with the specific SNARE-dependent exocytosis inhibitor, tetanus toxin $(0.1 \mu M, n=6)$. (b) Suppression of EPSCs was abolished by intracellular loading of the specific dynamin-dependent endocytosis inhibitor, DI5 ( $2 \mathrm{mM}, n=6)$. The persistent changes induced by $1.5 \mathrm{mM}$ glycine (control in c) were borrowed from the data in Figure I (c, d) Statistical plots of data showing abolishment of Gly-LTP and LTD by the exocytosis blocker, $T e T x$, and the endocytosis blocker, DI5, respectively. ** $P<0.01$, compared between the indicated groups.

\section{DISCUSSION}

\section{Involvement of GlyRs in LTD Induction}

Glycine is one of the main inhibitory neurotransmitters in the CNS in many brain regions, including the hippocampus where excitatory glutamatergic synapses are highly expressed. Glycine exerts its inhibitory effect mainly through the activation of GlyRs and the subsequent opening of GlyRgated chloride channels. In the present study, we demonstrated that, in contrast to the induction of LTP by glycine at relatively low concentrations, glycine at high
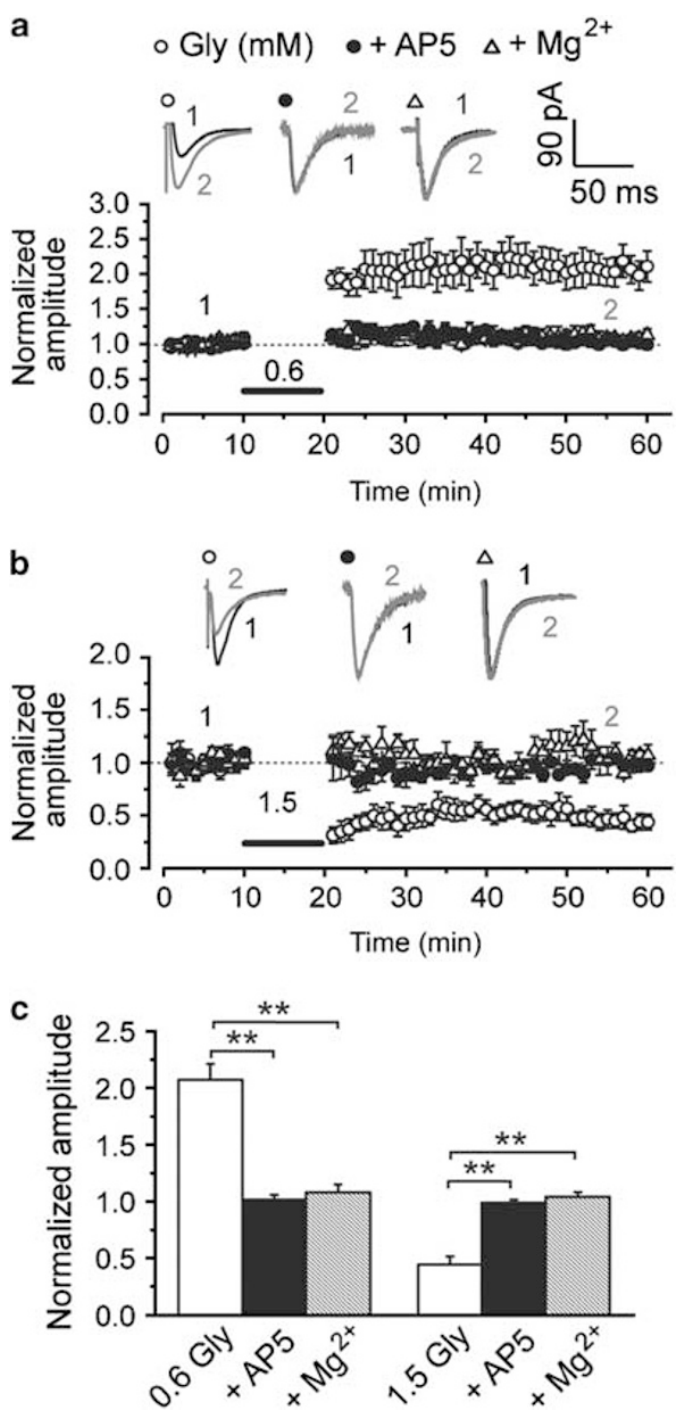

Figure 7 Both Gly-LTP and LTD were dependent on NMDAR activation. (a) Co-application of glycine $(0.6 \mathrm{mM})$ with a specific competitive NMDAR antagonist D,L-AP5 (100 $\mu \mathrm{M}, n=6)$ or application of glycine $(0.6 \mathrm{mM})$ in ACSF containing I $\mathrm{mM} \mathrm{Mg}^{2+}(n=6)$ completely abolished LTP of EPSCs. (b) Co-application of glycine ( $1.5 \mathrm{mM}$ ) with AP5 $(n=6)$ or application of glycine $(1.5 \mathrm{mM})$ in ACSF containing $1.0 \mathrm{mM} \mathrm{Mg}{ }^{2+}(n=6)$ completely abolished the suppression of EPSCs. (c) Statistical plotting of data displaying the effect of antagonizing NMDAR functions by AP5 or $1.0 \mathrm{mM} \mathrm{Mg}$ ' on persistent changes in EPSCs induced by glycine at 0.6 or $1.5 \mathrm{mM}$. ** $P<0.01$, compared between the indicated groups.

concentrations instead produced LTD. GlyRs activation and modulation accounted for the persistent suppressive effect displayed by glycine. These findings lend support to our hypothesis that the two distinct binding sites of glycine in NMDARs (site B) and GlyRs (site A) have critical roles in Gly-LTP and Gly-LTD, respectively. GlyRs blockade uncovered the excitatory effect exerted by glycine on site $\mathrm{B}$ and reversed the LTD to LTP. D-serine selectively acts on site B in NMDARs and its effect is more potent than glycine, and taurine can activate GlyRs (site A) as glycine does. If our hypothesis is true, we should observed D-serine-induced LTP and taurine-induced LTD. We indeed obtained LTP induced by D-serine at $100 \mu \mathrm{M}$ (Supplementary Figure S10). However, we only observe LTP, but not LTD of EPSCs 
induced by taurine $(6 \mathrm{mM})$. This result could be ascribed to the fact that GlyR is not the only target of taurine. Besides GlyRs, taurine could also act on taurine transporter, calcium channel, and taurine receptors which might exist and display various effects (López-Colomé et al, 1991; del Olmo et al, 2000, 2003; Sergeeva et al, 2003). Our observations that Gly-LTD was totally abolished by $1.0 \mathrm{mM} \mathrm{Mg}^{2+}$ perfusate proved that NMDARs also had an important role in LTD induction. The possible interaction between GlyRs and NMDARs could be a potential mechanism underlying Gly-LTD. Although till now there is no evidence for direct interaction between these two receptors, GlyR activation by glycine may indirectly regulate NMDAR function. As a result, AMPARs internalization, which requires NMDAR activation and subsequent $\mathrm{Ca}^{2+}$ influx, was motivated. The downregulation of NMDARs, either through the regulation of NMDAR gating or NMDAR endocytosis as previously reported (Nong et al, 2003), might have accounted for this modulation. Intracellular $\mathrm{Cl}^{-}$ concentrations are higher in neurons from immature animals. In the present study, we also examined whether Gly-LTD could still be induced using a pipette solution with a high $\mathrm{Cl}^{-}$solution (136.5 mM; Supplementary Figure S1). Interestingly, glycine at a concentration as low as $0.6 \mathrm{mM}$ elicited Gly-LTD with a depression magnitude comparable to the depression magnitude induced by $1.5 \mathrm{mM}$ glycine with $21.5 \mathrm{mM}$ intracellular $\mathrm{Cl}^{-}$. It is notable that glycine at $0.6 \mathrm{mM}$ induced Gly-LTP with $17.5 \mathrm{mM}$ intracellular $\mathrm{Cl}^{-}$. Because intracellular $\mathrm{Cl}^{-}$concentrations are higher in neurons from immature animals, it is possible that GlyR activation in LTD has a greater impact in younger animals.

Our present results reveal new function of GlyRs on baseline EPSC in resting CA1 pyramidal neurons in hippocampus. Activation of GlyRs by high-level glycine induces persistent depression of EPSCs. These findings are complementary to a recent study which mainly examined the activity-dependent modulation of glycine in plasticity in the same neurons (Keck et al, 2008). Suppression of GlyRs function accounts for rate-dependent efficacy and increases the amplitude of EPSCs. Reduction of GlyRs suppression function facilitates LTD induced by repetitive paring of postsynaptic spike and presynaptic stimulations, whereas activation of GlyRs with high-level glycine (1.0 mM) counteracts this form of LTD. In this study, it is possible that activation of GlyRs by $1.0 \mathrm{mM}$ glycine (in $4.0 \mathrm{mM} \mathrm{Mg}{ }^{2+}$ -containing perfusing medium) suppresses excitatory neurotransmission, as demonstrated by a recent study (Song et al, 2006). This effect might occur more rapidly than LTD induction and thus excludes further LTD elicited by $10 \mathrm{~Hz}$ induction protocol. The differential roles of GlyRs activation in modulating basal excitatory neurotransmission and plasticity, as indicated by present results and White lab (Keck et al, 2008), might also suggest distinct mechanisms underlie these two observations.

The simplest explanation for incomplete reversal of plasticity polarity is that the strychnine concentrations we used did not completely block the glycine currents as shown in Supplementary Figure S3. However, we still could not exclude the possibility that other factors may also have a role in LTD induction. Consistent with this hypothesis, the simultaneous blockade of both presynaptic and postsynaptic GlyR functions by the whole slice perfusion of GlyR blockers, along with postsynaptic $\mathrm{Cl}^{-}$manipulation completely switched LTD to LTP, which suggested a potential role of presynaptic GlyRs in Gly-LTD induction. In addition, the manipulation of intracellular $\mathrm{Cl}^{-}$ concentration could also affect other channels that are permeable to $\mathrm{Cl}^{-}$.

A previous study in cultured hippocampal neurons demonstrated that glycine at concentrations as high as $1.0 \mathrm{mM}$ produces LTP. However, these results were obtained in the presence of the GlyR antagonist, strychnine, in all of the solutions to deliberately exclude the potential activation of GlyRs (Lu et al, 2001). A recent study reported the acute suppressive action of both EPSCs in CA1 pyramidal neurons and IPSCs in interneurons by glycine (Song et al, 2006). This inhibitory effect only lasted for around $15 \mathrm{~min}$, and the EPSCs recovered after the washout of glycine. Here, we observed a persistent depression of EPSCs. This inconsistency is likely attributable to differences in the experimental protocols applied in the two studies. In this study, we applied glycine for $10 \mathrm{~min}$ in an $\mathrm{Mg}^{2+}$-free perfusate to
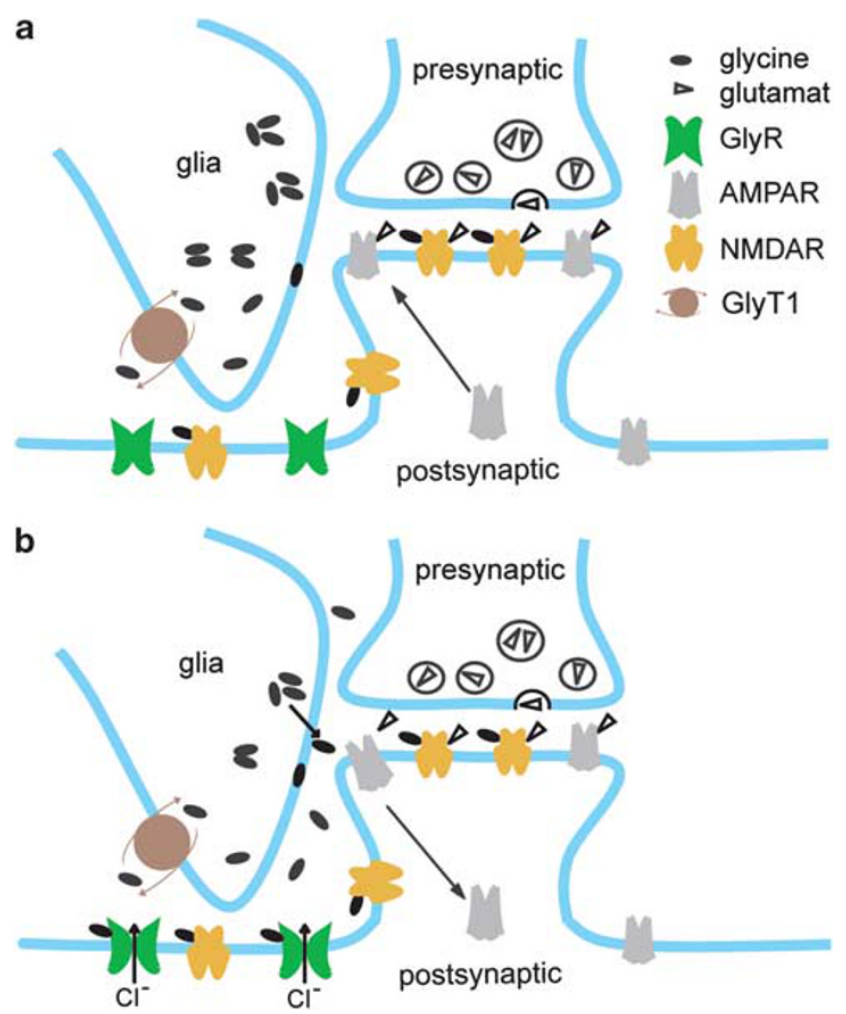

Figure 8 A model of the dose-dependent bidirectional regulation of EPSCs by glycine. (a) Because of differences in glycine's affinity for the NMDAR co-agonist binding site (site B) and GlyRs (site A), endogenous glycine prefers to exert its effect through the NMDAR co-agonist binding site. When glycine is at a concentration that barely activates GlyRs, glycine displays a primarily excitatory effect on EPSCs through the potentiation of NMDAR function. (b) Some physiological or pathophysiological states, such as dysfunction of the glycine transporter, can cause accumulation of glycine in the synaptic cleft. As a result, glycine spills over to neighboring extrasynaptic sites where most GlyRs in the hippocampus are located. Subsequent activation of GlyRs inhibits EPSCs. This effect may be stronger than the excitatory effect mediated through the NMDAR binding site and the overall effect exerted by glycine is depression of EPSCs. Thus, the bidirectional regulation by glycine at different concentrations represents an efficient route to maintain the excitation-inhibition balance. 
briefly activate synaptic NMDARs. In contrast, the authors of the other study applied glycine in $4.0 \mathrm{mM} \mathrm{Mg}^{2+}$ ACSF. These results suggest that the persistent inhibitory effect by glycine depends on the activation of synaptic NMDARs.

\section{A Model for the Bidirectional Regulation of EPSCs by Glycine}

Our present results strongly suggest that concentration is a very important factor for the effect of glycine on basal glutamatergic neurotransmission. This is largely attributable to differences in the affinity of glycine for the NMDAR co-agonist binding site (site B) and GlyRs (site A). NMDARs have a substantially higher affinity for glycine than for GlyRs (Chattipakorn and McMahon, 2002; Vyklicky et al, 1990). Therefore, endogenous glycine typically acts through the NMDAR co-agonist binding site. Under this condition, glycine mainly displayed an excitatory effect on EPSCs that was mediated by the potentiation of NMDAR function (Figure 8a). Some physiological or pathophysiological states can cause an accumulation of glycine in the synaptic cleft, such as dysfunctional glycine transporters. As a result, glycine spills over to neighboring extrasynaptic sites where most functional GlyRs are located in the hippocampus. The subsequent activation of GlyRs inhibits EPSCs. This effect may be stronger than the excitatory effect mediated through the NMDAR binding site and the total effect mediated by glycine was a depression of EPSCs (Figure $8 b$ ). Thus, the bidirectional regulation by glycine at different concentrations represented an efficient route to the maintenance of the excitation-inhibition balance.

Our findings reveal an important function of GlyR activation and point to new clues that GlyRs could be a potential target for correcting unwanted synaptic plasticity under pathological conditions, including brain ischemia.

\section{ACKNOWLEDGEMENTS}

We thank Dr Gong Chen at Pennsylvania State University, Dr Yu Tian Wang at the University of British Columbia, Dr Wei-Yang Lu and Dr Michael Jackson at the University of Western Ontario for constructive discussions and comments on the manuscript. This work was supported by grants to WL from the National Natural Science Foundation of China (NSFC, No. 31025011 and No. 30970934), the Major State Basic Research Program of China (2010CB912002) and the Education Department of Jiangsu Province (No. 08KJA180004).

\section{DISCLOSURE}

The authors declare no conflict of interest.

\section{REFERENCES}

Barth A, Nguyen LB, Barth L, Newell DW (2005). Glycine-induced neurotoxicity in organotypic hippocampal slice cultures. Exp Brain Res 161: 351-357.

Bashir ZI, Tam B, Collingridge GL (1990). Activation of the glycine site in the NMDA receptor is necessary for the induction of LTP. Neurosci Lett 108: 261-266.
Boehm J, Kang MG, Johnson RC, Esteban J, Huganir RL, Malinow $\mathrm{R}$ (2006). Synaptic incorporation of AMPA receptors during LTP is controlled by a PKC phosphorylation site on GluR1. Neuron 51: 213-225.

Carroll RC, Beattie EC, von Zastrow M, Malenka RC (2001). Role of AMPA receptor endocytosis in synaptic plasticity. Nat Rev Neurosci 2: 315-324.

Chattipakorn SC, McMahon LL (2002). Pharmacological characterization of glycine-gated chloride currents recorded in rat hippocampal slices. J Neurophysiol 87: 1515-1525.

Constantine-Paton M, Cline HT (1998). LTP and activitydependent synaptogenesis: the more alike they are, the more different they become. Curr Opin Neurobiol 8: 139-148.

Cubelos B, Gimenez C, Zafra F (2005). Localization of the GLYT1 glycine transporter at glutamatergic synapses in the rat brain. Cereb Cortex 15: 448-459.

Danglot L, Rostaing P, Triller A, Bessis A (2004). Morphologically identified glycinergic synapses in the hippocampus. Mol Cell Neurosci 27: 394-403.

Danysz W, Parsons CG (1998). Glycine and N-methyl-D-aspartate receptors: physiological significance and possible therapeutic applications. Pharmacol Rev 50: 597-664.

del Olmo N, Galarreta M, Bustamante J, Martin del Rio R, Solis JM (2000). Taurine-induced synaptic potentiation: role of calcium and interaction with LTP. Neuropharmacology 39: 40-54.

del Olmo N, Handler A, Alvarez L, Bustamante J, Martin del Rio R, Solis JM (2003). Taurine-induced synaptic potentiation and the late phase of long-term potentiation are related mechanistically. Neuropharmacology 44: 26-39.

Globus MY, Busto R, Martinez E, Valdes I, Dietrich WD, Ginsberg MD (1991). Comparative effect of transient global ischemia on extracellular levels of glutamate, glycine, and gamma-aminobutyric acid in vulnerable and nonvulnerable brain regions in the rat. J Neurochem 57: 470-478.

Jaskolski F, Martin S, Henley JM (2007). Retaining synaptic AMPARs. Neuron 55: 825-827.

Johnson JW, Ascher P (1987). Glycine potentiates the NMDA response in cultured mouse brain neurons. Nature 325: 529-531.

Kang N, Xu J, Xu Q, Nedergaard M, Kang J (2005). Astrocytic glutamate release-induced transient depolarization and epileptiform discharges in hippocampal CA1 pyramidal neurons. J Neurophysiol 94: 4121-4130.

Keck T, Lillis KP, Zhou Y, White JA (2008). Frequency-dependent glycinergic inhibition modulates plasticity in hippocampus. J Neurosci 28: 7359-7369.

Keck T, White JA (2009). Glycinergic inhibition in the hippocampus. Rev Neurosci 20: 13-22.

Kemp JA, Leeson PD (1993). The glycine site of the NMDA receptor - five years on. Trends Pharmacol Sci 14: 20-25.

Lasley SM (1991). Roles of neurotransmitter amino acids in seizure severity and experience in the genetically epilepsy-prone rat. Brain Res 560: 63-70.

Lee SH, Simonetta A, Sheng M (2004). Subunit rules governing the sorting of internalized AMPA receptors in hippocampal neurons. Neuron 43: 221-236.

Li Y, Krupa B, Kang JS, Bolshakov VY, Liu G (2009). Glycine site of NMDA receptor serves as a spatiotemporal detector of synaptic activity patterns. J Neurophysiol 102: 578-589.

López-Colomé AM, Fragoso G, Salceda R (1991). Taurine receptors in membranes from retinal pigment epithelium cells in culture. Neuroscience 41: 791-796.

Lu W, Man H, Ju W, Trimble WS, MacDonald JF, Wang YT (2001). Activation of synaptic NMDA receptors induces membrane insertion of new AMPA receptors and LTP in cultured hippocampal neurons. Neuron 29: 243-254.

Luscher C, Xia H, Beattie EC, Carroll RC, von Zastrow M, Malenka $\mathrm{RC}$ et al (1999). Role of AMPA receptor cycling in synaptic transmission and plasticity. Neuron 24: 649-658. 
Malenka RC, Bear MF (2004). LTP and LTD: an embarrassment of riches. Neuron 44: 5-21.

Martina M, Gorfinkel Y, Halman S, Lowe JA, Periyalwar P, Schmidt CJ et al (2004). Glycine transporter type 1 blockade changes NMDA receptor-mediated responses and LTP in hippocampal CA1 pyramidal cells by altering extracellular glycine levels. J Physiol 557: 489-500.

Morishita W, Marie H, Malenka RC (2005). Distinct triggering and expression mechanisms underlie LTD of AMPA and NMDA synaptic responses. Nat Neurosci 8: 1043-1050.

Newell DW, Barth A, Ricciardi TN, Malouf AT (1997). Glycine causes increased excitability and neurotoxicity by activation of NMDA receptors in the hippocampus. Exp Neurol 145: 235-244.

Nong Y, Huang YQ, Ju W, Kalia LV, Ahmadian G, Wang YT, Salter MW (2003). Glycine binding primes NMDA receptor internalization. Nature 422: 302-307.

Oliver MW, Larson J, Lynch G (1990). Activation of the glycine site associated with the NMDA receptor is required for induction of LTP in neonatal hippocampus. Int J Dev Neurosci 8: $417-424$.

Riekki R, Pavlov I, Tornberg J, Lauri SE, Airaksinen MS, Taira T (2008). Altered synaptic dynamics and hippocampal excitability but normal long-term plasticity in mice lacking hyperpolarizing GABAA receptor-mediated inhibition in CA1 pyramidal neurons. J Neurophysiol 99: 3075-3089.

Sergeeva OA, Chepkova AN, Doreulee N, Eriksson KS, Poelchen W, Mönnighoff I, HellerStilb B, Warskulat U, Häussinger D, Haas HL (2003). Taurine-induced long-lasting enhancement of synaptic transmission in mice: role of transporters. J Physiol 550: 911-919.

Song W, Chattipakorn SC, McMahon LL (2006). Glycine-gated chloride channels depress synaptic transmission in rat hippocampus. J Neurophysiol 95: 2366-2379.

Tojima T, Akiyama H, Itofusa R, Li Y, Katayama H, Miyawaki A et al (2007). Attractive axon guidance involves asymmetric membrane transport and exocytosis in the growth cone. Nat Neurosci 10: 58-66.

Tsen G, Williams B, Allaire P, Zhou YD, Ikonomov O, Kondova I et al (2000). Receptors with opposing functions are in postsynaptic microdomains under one presynaptic terminal. Nat Neurosci 3: 126-132.

Vyklicky Jr L, Benveniste M, Mayer ML (1990). Modulation of N-methyl-D-aspartic acid receptor desensitization by glycine in mouse cultured hippocampal neurones. J Physiol 428: 313-331.

Wallis RA, Panizzon KL, Nolan JP (1995). Glycine-induced CA1 excitotoxicity in the rat hippocampal slice. Brain Res 685: 115-125.

Westergren I, Nystrom B, Hamberger A, Nordborg C, Johansson BB (1994). Concentrations of amino acids in extracellular fluid after opening of the blood-brain barrier by intracarotid infusion of protamine sulfate. J Neurochem 62: 159-165.

Wilcox KS, Fitzsimonds RM, Johnson B, Dichter MA (1996). Glycine regulation of synaptic NMDA receptors in hippocampal neurons. J Neurophysiol 76: 3415-3424.

$\mathrm{Xu}$ TL, Gong N (2010). Glycine and glycine receptor signaling in hippocampal neurons: diversity, function and regulation. Prog Neurobiol 91: 349-361.

Zhang HX, Lyons-Warren A, Thio LL (2009a). The glycine transport inhibitor sarcosine is an inhibitory glycine receptor agonist. Neuropharmacology 57: 551-555.

Zhang HX, Hyrc K, Thio LL (2009b). The glycine transport inhibitor sarcosine is an NMDA receptor co-agonist that differs from glycine. J Physiol 587: 3207-3220.

Zhang LH, Gong N, Fei D, Xu L, Xu TL (2008). Glycine uptake regulates hippocampal network activity via glycine receptor-mediated tonic inhibition. Neuropsychopharmacology 33: 701-711.

Zoghbi HY, Gage FH, Choi DW (2000). Neurobiology of disease. Curr Opin Neurobiol 10: 655-660.

Supplementary Information accompanies the paper on the Neuropsychopharmacology website (http://www.nature.com/npp) 